\title{
Design Problem of Flat Belts in Internal Transport Systems
}

\author{
G. Domek, A. Kołodziej, K. Warmbier, E. Gawrońska
}

\begin{abstract}
The work deals with the problem of using flat belts in internal transport systems. There are many modern solutions for such belts, but to use them in demanding logistics systems, it is necessary to analyze the basic problems associated with coupling in a belt transmission. Then fast movement and transport problems can be solved. All these parameters contribute to the new approach to the belt-pulley coupling model, which was proposed in this paper.
\end{abstract}

Keywords: Internal Transport, Flat Belts, Conveyor Belts.

\section{INTRODUCTION}

Gears with flat belts were one of the first tendom gears. Nonetheless, after other types of belts were introduced for torque transmission, their role was limited to acting as conveyer belts. Flat belts were often called ,transporting and processing belts" which was a rather unfortunate translation from German that diminished their importance by misrepresenting their possible uses. Their scope of functions seemed to be reduced to: transporting products from a point $\mathrm{A}$ to a point $\mathrm{B}$, and being part of production processes.

However, in recent years, the functions and the quality of gears with flat belts have begun to change significantly. Structures were created that could meet the highest requirements of modern machines [3] and in some machine drives they started to reach the highest velocities, unattainable for other types of belts. Moreover, gears with flat belts are nowadays also used in presses, which are used for pressing wooden and synthetic panels under high pressure; and also in drives of the highest torque. [2](Fig.1).

Manuscript received on April 22, 2021.

Revised Manuscript received on April 30, 2021.

Manuscript published on June 30, 2021.

* Correspondence Author

Grzegorz Domek*, Department of Mechatronics, Kazimierz Wielki University, Chodkiewicza 30, 85-064, Bydgoszcz, Poland, E-mail: gdomek@ukw.edu.pl,

Andrzej Kolodziej, Depatament of Mechanical Engineering, Calisia University, Nowy Świat 4,62-800 Kalisz, Poland, E-mail: ia.kolodziej@pwsz.kalisz.pl,

Krzysztof Warmbier, Instytut of Materials Engineering, Kazimierz Wielki University, Chodkiewicza 30, 85-064, Bydgoszcz, Poland, E-mail: gdomek@ukw.edu.pl,

Elżbieta Gawrońska, Department of Mechanical Engineering and Informatics, Częstochowa Technical University, Dąbrowskiego 69, 42-201 Częstochowa, Poland, E-mail: gawrońska@icis.pcz.pl.

(c) The Authors. Published by Blue Eyes Intelligence Engineering and Sciences Publication (BEIESP). This is an open access article under the CC BY-NC-ND license (http://creativecommons.org/licenses/by-nc-nd/4.0/)

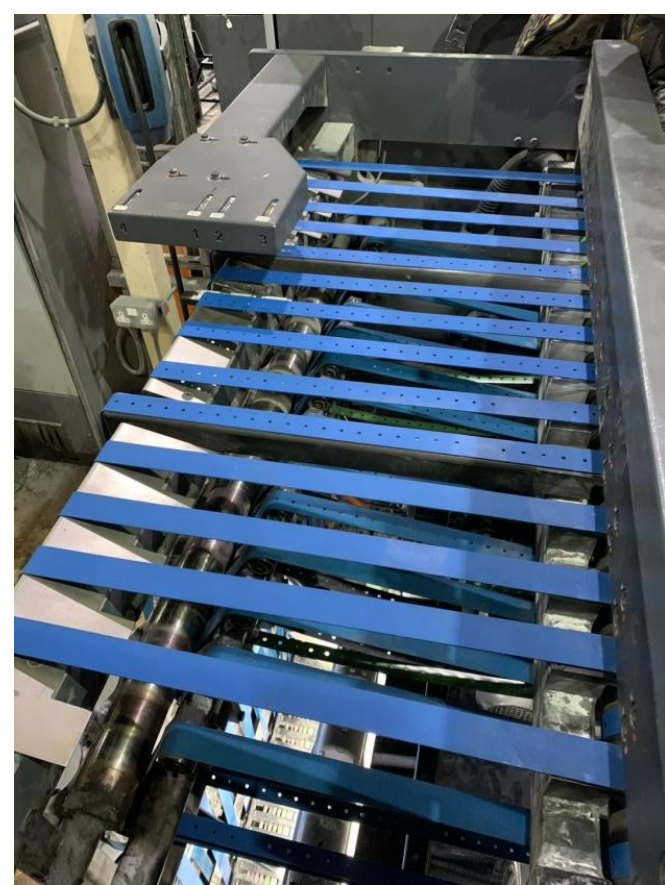

Fig. 1. A system of flat conveyer belts in a packaging factory

Flat belts can be found in some of ,the heaviest" drive systems runging from stone mill drives, through hydroelectric power plants and sawmills, to drives of powerful wood chippers. They are elements of the drive technology for the highest speeds. For instance, in propulsion systems in printing and textile industries, some belts move at speeds of the order of hundreds of meters per second. In addition to that, especially in the printing industry, besides the drive function, the belts also act as conveyers. What distinguishes flat belts from drive belts is their ability to deliver the largest gear ratios and their ability to simultaneously drive multiple shafts. Moreover, flat belts are multipliers, hence, they prove useful in power generators; additionally they are of use in simple control systems where they are used as reducers.

The drives of many shafts are mainly various types of printing systems, albeit they can also serve as roller stream conveyors. Additionally, it is worth noting that whilst functioning as the former and the latter, the flat belt drive simultaneously acts as an overload clutch for the system. Hence, the belts, if selected properly, are not immediately damaged, should the drive be blocked. Nonetheless, the biggest advantage of flat belts in propulsion systems is the compatibility of work of shafts located in different planes, as well as rotating in different directions.

\section{Published By:}

Blue Eyes Intelligence Engineering and Sciences Publication

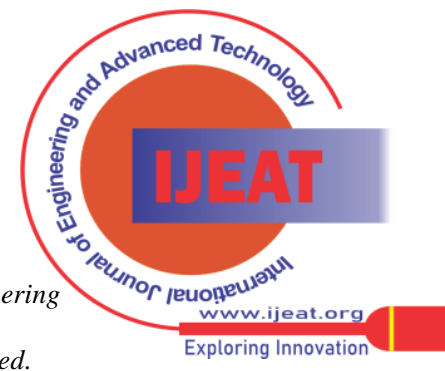




\section{THE USE OF FLAT BELTS IN TRANSPORT}

Flat belts, due to their mechanical properties, are commonly used in conveyor systems in which other tie rods do not meet the functional requirements [1]. For instance, they can be found in conveyors transporting products at high speeds. Since belts used in these systems are exposed to significant abrasive wear, and preform work in difficult environmental conditions, only the use of flat belts can ensure lasting and durable construction of the conveyor [3]. Nonetheless, it is also worth mentioning that besides conveyor belts, drive belts can also work on conveyors. That type of belts is mostly used in cases when it is not possible to select a sufficiently durable solution from the group of conveyor belts [2 ](Fig.2).

As for setting the belt in motion, the value of the friction coefficient between the propeller shaft and the wheel is quite important. Followingly, should the outer shaft is used for propulsion, the diameter ought to be minimized in order to ease the collection of the conveyed material from the conveyor. [4,5]. Nevertheless, the diameter of the shaft cannot be smaller than its permissible value due to the elasticity of the tendon.

Another crucial factor in setting the dimensions of drive shafts is contamination. Occurrences of dirt or residue from transported materials may significantly hinder the transporting process, thus, drive shafts with a maximum diameter should be used and placed under the conveyor, to minimize the risk of blockage. In addition to those, for maximum stability and security, rollers are used to increase the angle of the drive shaft.

Scrapers may be used in the construction of conveyors to remove residues of transported material from the belt. They should be placed outside the belt on the curve around the front or propeller shaft. If the scraper also cleans the inside of the belt, it should be located in front of the return shaft.

Furthermore, conveyor designs often require additional belt correction systems. The barrel wheeliness of the drive wheel will not be sufficient for proper running if there is an additional non-axial load on the dorsal side of the belt. The recommended barrel shape of belt conveyor shafts depends on their geometrical dimensions [6]

a)

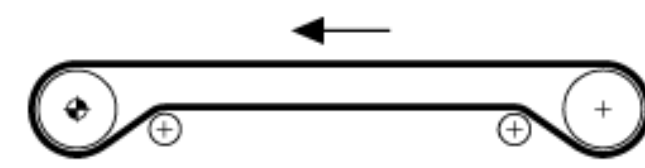

b)

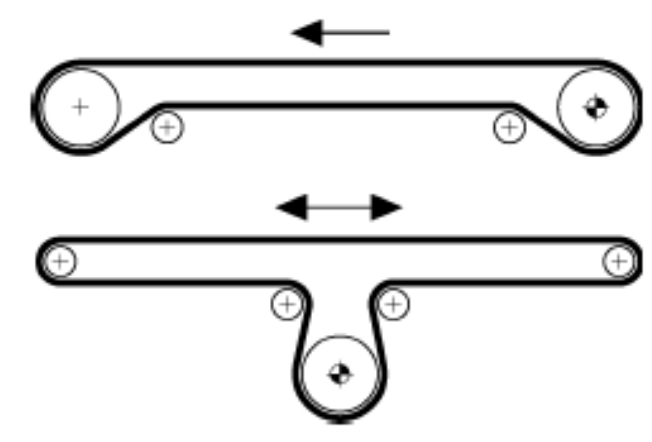

c)

Fig. 2. Basic systems of belt operation on the conveyor: a) pulled belt, b) pushed belt on the conveyor, c) reverse working belt.
The inside diameter of shaft D1 should differ from the outside D2 according to the equation:

Ø D1 - Ø D2 = 1\% x D1, and should not exceed 4 mm. Depending on the shaft length, the cone-cylinder-cone division should be:

Length <400 mm: 1/3 - 1/3 - 1/3 400 - 800 mm: 1/4 - 1/2 - 1/4 800 - 1200 mm: $1 / 5-3 / 5-1 / 5$

$1200-1600 \mathrm{~mm}: 1 / 6-4 / 6-1 / 6$

> $1600 \mathrm{~mm}$ : both $300 \mathrm{~mm}$ conical parts

Another solution used in conveyors are guide rollers. To ensure the quality of belt movement, the geometry of the entire conveyor structure is, of course, important, nonetheless, the last roller in front of the turning shaft performs an essential - steering function, due to that the roller it is often called the steering wheel. By changing the position of this roller in relation to the belt, the right gear is exerted on the turning wheel, hence, on the surface of the conveyor. The distance between the axis of this roller and the return shaft should be: 100 - $400 \mathrm{~mm}$; its wrap arc between: 15 - $30^{\circ}$; the adjustment of its edge position should not exceed $10 \%$ of the belt width.

In order to improve the efficiency of this system, it is recommended to increase the friction coefficient of two materials. The guide roller can be adjusted "manually" or equipped with a system that recognizes the position of the belt and automatically adjusts its position. In guiding wedges, used in conveyors, the belt moves at a speed of less than $1 \mathrm{~m} /$ s. This prevents the belt from falling off the conveyor despite occurrences of variable loads on the conveyor or transverse forces on the belt (Fig.3).

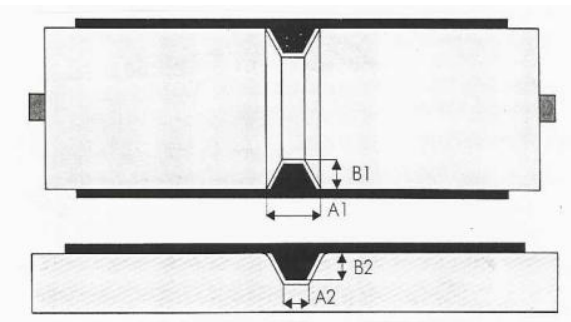

Fig. 3. Preparing the furrow in the conveyor and shafts.

In the event of sudden transverse loads occurring when the product is introduced onto the conveyor, additional guide strips along the edge of the belt can be used. This solution, however, cannot be the main way to control the course of the belt, since these strips would quickly cause damage the belt.

The correct operation of the belt also depends on entering the correct preload force. Usually this is the force needed to extend the belt from $1 \%$ to $2 \%$. Therefore, the conveyor should be equipped with a tensioning system, because not only by moving the outer shafts one can lose the conveyor geometry, but also damage the belt. It is also important to note, that the extreme shafts cannot be tensioned, if they are part of the conveyor system.
Published By:

Blue Eyes Intelligence Engineering and Sciences Publication (C) Copyright: All rights reserved.

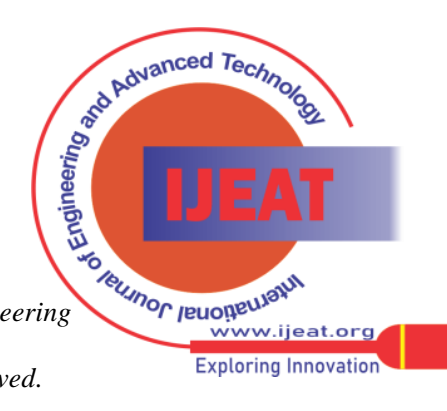




\section{FLAT BELTS IN ELEVATOER AND CONTROL SYSTEMS}

In recent years, a whole range of flat belts has been developed and specialized for use in elevators and manipulators. That includes flat belts with a steel cord coated with high-quality polyurethane and Kevlar cord. Nonetheless, coating technology forced that the steel cables are supported in the production process, which resulted in cracks in the material, similar to those in the PU toothed belts. Such belts, moving at high speeds on wheels, emitted much noise. Thus, the arrangement of fissures along the belt width schewron was studied, which helped reduce the level of noise emissions caused by them. To meet the expectations of their clients, Continental has developed a new production line, which aimed to produce belts without cracks.

Another recent example of improvements in the production of belts is a technological line, called Polyrob, that was dedicated to the production of grooved elevator belts. These belts work with appropriately shaped wheels which significantly improves the way the belts run on the wheels. Moreover, systems of supervision over the technical condition of the belts in the elevator have been developed; which significantly reduced the duration of elevators' inspections and allowed for ongoing monitoring of their technical condition.

Flat belts are also increasingly used in storage systems. Logistics 4.0 is a challenge for both flat and toothed belt systems. Feeding systems, manipulators and trolleys are nowadays used in hundreds of warehouses around the world. In some the fastest sorting systems, exempli gratia, in the AMAZON sorting plants, there is an abundance of polyurethane belts with Kevlar cord from NITTA. That is, of course, owing to their outstanding features such as: durability, dimensional stability, travel over considerable distances, and low noise emission. All of these combined make these belts irreplaceable (Fig.4).

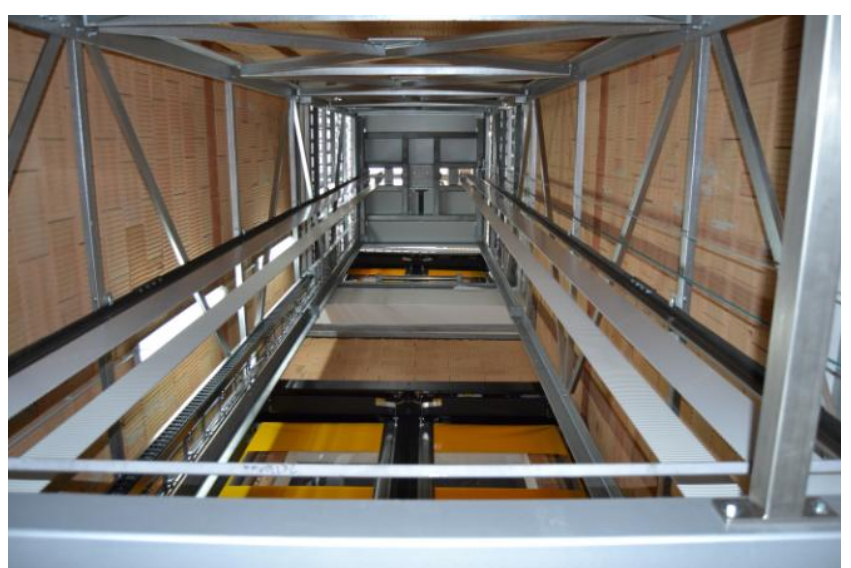

Fig. 4. An elevator using belts with a steel cord

Recently, this has been the most dynamically developing area of application of flat belts, however it has not been an entirely "new" topic. The friction coupling of a weightless thread with a wheel was already described by Euler, and although this problem has been raised by many authors in their publications later, the development of the Euler formula is what allows people nowadays to understand the phenomena occurring in the flat belt transmission.

In the actual transmission process, similarly to Euler's work, one should indicate the relationship between the belt and the wheel and between the belt material and the cord.

Modern types of fibers used in the support layer of the belt have better and better mechanical properties than ever before. The ratio of active to passive elongation approaches unity. Thus, the quality of the coupling depends on the belt to wheel friction coefficient $\mu_{\mathrm{z}}$ and friction inside the belt $\mu_{\mathrm{w}}$ Gearbox coupling can be considered in the following way:

$$
\frac{d S_{1}}{d S_{2}}=e^{\beta \mu},
$$

where:

$$
\mu=\mu_{z}+\mu_{w}
$$

while $-\beta$ is the angle of wheel wrap expressed in radians.

The tensile strength of the belt support layer, therefore, improves the running surface conditions, since it is not stretched and wear damage does not occur. However, the problems of modern belts are rheological phenomena and the coherence of the cord with the belt material, as well as the linear speed of the belt. If the ratio of the elongation of the active cable $\Delta L_{C}$ to the passive $\Delta L_{b}$ tends to unity, the material deformation below the support layer consisting of compression and horizontal displacement with respect to the cord should be considered.

Hence, if:

$$
\frac{\Delta L c}{\Delta L b} \gg 1
$$

Then the coupling in a gear with a flat belt will be:

$$
\frac{d S_{1}}{d S_{2}}=f\left(\sigma, h, D, F_{r}, F_{o}\right)
$$

Which is a function of the belt material - $\sigma$, the contact surface with the wheel - $D$, the circumferential force - $F_{o}$, the preload force - $F_{r}$, and the height of the belt layer below the support layer $-h$.

From that it can be seen that what seems to be the main problem is moving the flat belt around the wheel; which has sadly caused a withdrawal of this type of transmission. Regardless of that, this problem has already been perfectly solved many years ago; and it is these belts that perform best the function of driving the wheels located in different planes (Fig.5).

Pulleys, at least driving wheels, should have a barrel shape. It is also possible to place $\mathrm{V}$ profiles on the running side of the belt cooperating with a properly shaped pulley, as in many systems there are already mechatronic systems correcting the course of the belt used. These systems correct the impact of the change in force on the belt over its width, as well as account for possible assembly and construction errors of mechanical systems. Nevertheless, there is a problem in the accuracy of the machines in which the belt transmissions are mounted, as they can, alongside improving the system's efficiency, cause damage to other types of belts $[5,6]$.

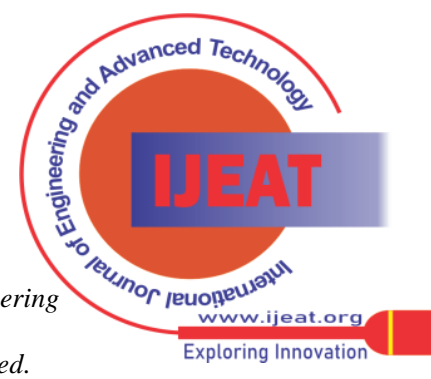




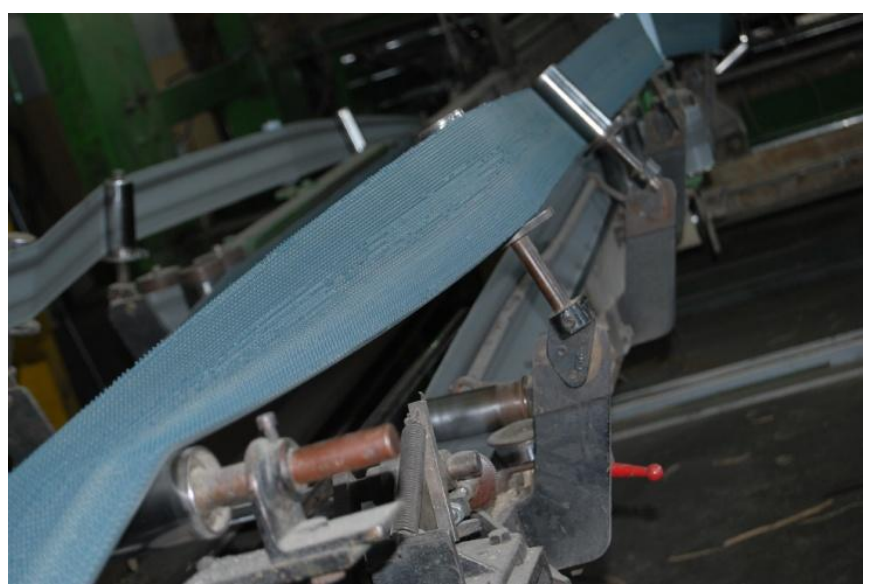

Fig. 5. Belt system in a paper packaging factory

For several years, designers have been using calculation programs supplied by belt manufacturers in choosing the parameters of belt transmission components [9]. Such programs have a number of implemented restrictions and fixed values. Therefore, the results obtained by their means do not coincide with the calculations made independently. The main failures of the software can be attributed to it excluding extreme calculation results (cases when the belt is too narrow, the wheel diameter is too small). However, it contains a number of confidential parameters determining the properties of the belt. Placing these parameters in the compiled program is a form of protection for the manufacturer against the dissemination of this knowledge, and revelation of their trade secrets.

Sometimes the best choice of belt for wheels seems to be choosing a belt according to the minimum wheel diameter on which it can work. In this way, the "strongest" belt that can work on a given wheel diameter is selected. Even though this tactic in choosing the right size of the belt may cause it to be oversized many times, it will certainly ensure that the belt fulfills its function and will not break on the wheels.

\section{CONCLUSION}

The right choice of a flat belt for a conveyor system ensures both quality of transport and durability of the entire system. This is important for safety, especially for high-speed passenger elevators. The quantities indicated in the formula for friction are of the utmost importance, yet they are not the only parameters affecting the quality of wheel-belt coupling. The quality of this coupling is most dependent on the mechanical properties of the tendon. Therefore, an ideal, unstretchable tendon, or at least one close to that is an object of the highest desire. As for modern belts, steel or carbon cord "Carbon" is used. That choice of wheel-belt friction pair should be close to unity. Nonetheless, there is also the abrasion of the mating surfaces which should be accounted for. The development of technological devices in the field of feeding, transporting and segregating products forces the need to develop structures based on both known and modified generators of translational, rotary or swing motion previously unknown or unused drives. Obtaining appropriate functional features while maintaining simple and reliable solutions is extremely desirable. It is necessary to introduce modifications or to devise new kinematic features of mechanical drives. One of the drives that are subject to very dynamic development are the transmission gears. The dynamics of the increase in the

use of tension gears goes both towards the development of belt designs and the emergence of new types of drives created by the association of known machine elements (non-classical gears, synchronous belts). It is then possible to obtain periodically variable kinematic and dynamic features [7]. Such solutions are very useful in control and transport technology. Development of the structure of these new drives is possible thanks to the development of methods and procedures for their design [8,9], manufacturing [10] and evaluation of their geometrical features $[11,12,13]$.

Regardless of how complex the fitting process of the belts and wheels could become, it is worth the consistent efforts to perfect it, as modern flat belts allow to solve many current problems. Mainly the ones so important in the twenty first century - the ones related to internal transport, both goods and people.

\section{REFERENCES}

1. G. Domek, M. Wilczyński, Modelling a timing belt pitch MATEC Web of Conferences - 2019, Vol. 254, art. no 01011,

2. G. Domek, A. Kołodziej M. Dudziak, T. Woźniak, Identification of the quality of timing belt pulleys, Procedia Engineering - 2017, Vol. 177, pp. 275-280,

3. G. Domek, A. Kołodziej M Wilczyński, P. Krawiec,The problem of cooperation of a flat belts with elements of mechatronic systems 55th International Scientific Conference on Experimental Stress Analysis 2017 - EAN 2017, May 30th - June 1st, 2017, Nový Smokovec, Slovakia. Book of abstracts / red. T. Kula, P. Frankovsky, R. Hunady, J. Bocko, F. Trebuna,. Kostka, Technical University of Kosice, 2017, p 706-711,

4. M. Łazarska, T. Woźniak, Z. Ranachowski, A. Trafarski, G. Domek, Analysis of acoustic emission signals at austempering of steels using neural networksMetals and Materials International - 2017, Vol. 23, iss. 3, pp. 426-433,

5. M Wilczyński, G. Domek, Influence of tension layer quality on mechanical properties of timing belts MATEC Web of Conferences - 2019, Vol. 254, art. no 05010,

6. D. Wojtkowiak, K. Talaśka, I. Malujda, G. Domek, Estimation of the perforation force for polymer composite conveyor belts taking into consideration the shape of the piercing punch, The International Journal of Advanced Manufacturing Technology - 2018, Vol. 98, pp. 2539-2561.

7. P. Krawiec, Analysis of selected dynamic features of a two-whwwled transmission system, Journal of Theoretical and Applied Mechanics, 55(2): 461-467.

8. P. Krawiec, A. Marlewski, Spline description of non-typical gears for belt transmissions, Journal of Theoretical and Applied Mechanics, 49(2) : 355-367.

9. P. Krawiec, A. Marlewski, Profile design of noncircular belt pulleys Journal of Theoretical and Applied Mechanics, 54(2): 561-570.

10. M. Kujawski, P. Krawiec, Analysis of Generation Capabilities of Noncircular Cog belt Pulleys on the Example of a Gear with an Elliptical Pitch Line. Journal of Manufacturing Science and Engineering-Transactions of the ASME 133(5), Article Number: 051006 .

11. P. Krawiec, Numerical Analysis of Geometrical Characteristics of Machine Elements Obtained Through CMM Scanning. Progress in Industrial Mathematics, Springer-Verlag, Berlin-Heidelberg: 925-930.

12. P. Krawiec, K. Waluś, Ł. Warguła, J. Adamiec, Wear evaluation of elements of V-belt transmission with the application of optical microscope, MATEC Web of Conferences 157,: 01009-1-8, doi.org/10.1051/matecconf/201815701009.

13. P. Krawiec, K. Waluś, L Warguła, J. Adamiec, Wear evaluation study of the multiple grooved pulleys with optical method, MATEC Web of Conferences,254,:01004-1-8,doi.org/10.1051/matecconf/20192540100

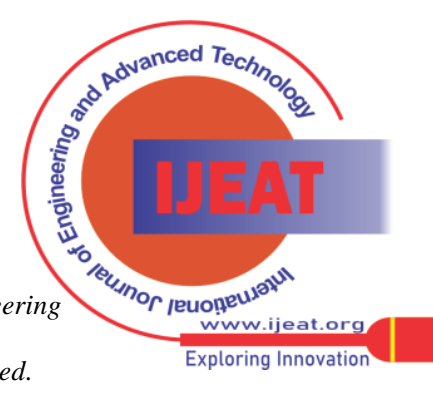




\section{AUTHORS PROFILE}

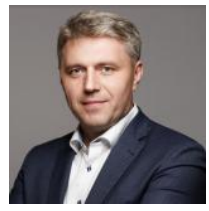

G. Domek, For almost 30 years I have been researching mechanical gears especially, gears with timing belts. I am the author of almost two hundred scientific publications and many patent studies. I have performed with scientific papers in many European countries, USA, China, Brazil, Mexico and Chile etc.. I am also the author of specialized production technologies that allow the production of advanced mechatronic belts.

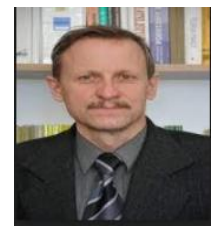

Krzysztof Warmbier, Institute of Materials Engineering, Kazimierz Wielki University, Chodkiewicza 3085-064 Bydgoszcz Poland

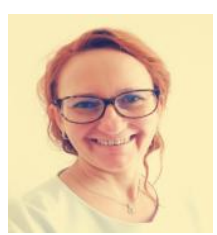

E. Gawrońska, I am a professor at the Częstochowa University of Technology at the Faculty of Mechanical Engineering and Computer Science. My research focuses on numerical modeling and computer simulations combining mechanical engineering, computer science, and materials engineering. In my work, I combine efficient numerical methods with highly efficient computational techniques to solve problems arising in thermo-mechanics and materials informatics.

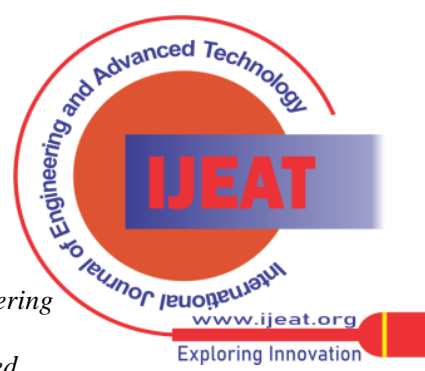

